\title{
DIREITO CONSTITUCIONAL DE RECORRER E A JUDICIALIZAÇÃO DA INEFICIÊNCIA EMPRESARIAL
}

CONSTITUTIONAL RIGHT TO APPEAL AND THE JUDICIALISATION OF BUSINESS INEFFICIENCY

Joaquim Falcão ${ }^{1}$ Ivar Hartmann ${ }^{2}$

Resumo: A judicialização das questões consumeristas atinge o Supremo Tribunal Federal por via dos juizados especiais há vários anos. Recentemente uma empresa do ramo de telefonia, a Oi, destacou-se pelo volume desproporcional de processos que levou ao tribunal. Ao analisar o perfil da litigância de direito do consumidor da Oi no Supremo, identificamos que a empresa envia o dobro de processos do segundo colocado no ranking de maiores litigantes, apesar de ter taxa de sucesso menor do que $0,07 \%$. No contexto da necessidade de adequada proteção dos direitos do consumidor, esse comportamento pode ser caracterizado como bullying processual e demanda novas atitudes por parte dos órgãos reguladores e do próprio Supremo.

Palavras-chave: Direito do consumidor. Judicialização. Supremo Tribunal Federal.

\begin{abstract}
The consumer rights lawsuits have reached the Brazilian Supreme Court through small claims courts for years. Recently, one phone company, Oi, stood out for the disproportional number of appeals it took to the court. We found that $\mathrm{Oi}$ brought double the number of appeals of the second most frequent appellant in consumer rights at the Supreme Court, even though Oi's success rate is lower than $0,07 \%$. In the context of appropriate consumer rights protection, this behavior can be characterized as lawsuit bullying and calls for a new attitude by the regulating agencies and the Supreme Court itself.
\end{abstract}

Keywords: Consumer rights. Lawsuits. Brazilian Supreme Court.

\footnotetext{
Doutor em Educação pela University of Génève; Mestre em Direito pela Harvard Law School; Diretor da Escola de Direito do Rio de Janeiro da Fundação Getúlio Vargas; Edifício Luiz Simões Lopes, Praia de Botafogo, 190, Botafogo, 22250-900, Rio de Janeiro, Rio de Janeiro, Brasil; joaquim.falcao@fgv.br

2 Mestre em Direito pela Pontifícia Universidade Católica do Rio Grande do Sul; Mestre em Direito pela Harvard Law School; doutorando em Direito pela Universidade Estadual do Rio de Janeiro; Professor Pesquisador da Fundação Getúlio Vargas do Rio de Janeiro; Coordenador do projeto Supremo em Números; ivarhartmann@gmail.com
} 


\section{Introdução}

A imensa carga de trabalho do Supremo Tribunal Federal é uma realidade enfrentada pelos ministros e seus gabinetes há cerca de duas décadas e é conhecida pela comunidade jurídica e pela população brasileira há pelo menos seis anos, em detalhe (FALCÃO; CERDEIRA; ARGUELHES, 2011). Nesse contexto, diversas questões importantes decorrentes do volume de processos julgados podem ser problematizadas, especialmente no contexto do papel do Supremo no sistema jurídico nacional e, talvez mais pertinente, sob o ponto de vista da atuação estratégica dos atores que atuam perante o Supremo. Essa atuação é retratada empiricamente, por exemplo, em modelos inferenciais sobre as chances de sucesso do Procurador Geral da República em ações do controle concentrado (HARTMANN; FERREIRA; REGO, 2016). Analisar o comportamento estratégico desses atores é especialmente pertinente quando se adota um modelo explicativo que não é exclusivamente legalista ("A PGR ajuíza Ações Diretas de Inconstitucionalidade para proteger direitos fundamentais diante de violações produzidas por incompatibilidades entre a legislação infraconstitucional e a Carta Magna"), mas que incorpora a atuação estratégica inclusive dos próprios ministros do Supremo. ${ }^{3}$

Nesse cenário, uma das questões mais relevantes é aquela que junta as duas dimensões: a volumosa carga de trabalho do Supremo, de um lado, e comportamentos estratégicos de atores dentro e fora do tribunal, de outro. Mais especificamente, neste artigo procuramos trazer dados empíricos inéditos sobre as escolhas de litigação recursal de uma grande empresa privada - a Oi - e a grande quantidade de recursos repetitivos que atribulam o Supremo anualmente. $\bigcirc$ foco nessa empresa justifica-se pela dimensão de seu pedido de recuperação judicial, o maior da história do Brasil, no valor de R\$ 65 bilhões (WIZIACK et al., 2016). Assim como as práticas gerenciais da Oi, suas práticas jurídicas e de litígio, ainda mais perante a mais alta Corte do País, são de relevância para o estudo do sistema brasileiro de justiça.

Nosso problema de pesquisa, portanto, é: qual o perfil de atuação da Oi no Supremo, especialmente sob o ponto de vista do volume de recursos protocolados, seus assuntos e taxa de sucesso? Nossa hipótese é que esse perfil seja destoante daquele das demais empresas privadas comparáveis - especialmente as de telefonia - e que o volume de processos não pode ser explicado pela taxa de sucesso da Oi em sua litigância recursal.

\section{Metodologia}

Para levantar dados sobre a atuação da Oi perante o Supremo Tribunal Federal adotamos metodologia de pesquisa empírica, com técnica quantitativa. Os dados foram obtidos usando a base de dados do projeto Supremo em Números. Trata-se de projeto de pesquisa do Centro de Justiça e

\footnotetext{
3 Se o modelo legalista não é suficiente para explicar o fenômeno Supremo, tampouco parece ser o modelo ideológico, conforme mostrado por Hudson e Hartmann (2017).
} 
Sociedade (CJUS) da Escola de Direito da Fundação Getúlio Vargas (FGV), no Rio de Janeiro. O projeto realiza macroanálises de todos os processos do Supremo desde 1988.

Pesquisas como esta, envolvendo grandes data sets, têm permitido aos juristas analisar de maneira muito mais minuciosas decisões judiciais (DIAMOND; MULLER, 2010). Nesse contexto, a disponibilidade de equipamento computacional, software e suporte técnico desempenha um papel-chave na viabilização de estudos empíricos pelos pesquisadores do Direito nos Estados Unidos (EPSTEIN; KING, 2003). A mesma situação prevalece no Brasil, onde faculdades de Direito começam a se adaptar a essa realidade, tornando o acesso a tal instrumental um elemento ainda mais importante de propostas de pesquisa (VERONESE, 2007). Os dados que subsidiam este artigo, bem como a diversificada produção do projeto Supremo em Números são possíveis somente em razão do uso de ferramental tecnológico potente. ${ }^{4}$

Ademais, a técnica de pesquisa escolhida pretende responder às perguntas de pesquisa mediante um olhar do todo - não de processos ou decisões isoladas do Supremo. $O$ novo movimento de estudos empíricos (YANOW; SCHWARTZ-SHEA, 2006) no Direito, no qual o presente artigo se insere, sempre se distinguiu do realismo jurídico e da sociologia jurídica em que as pesquisas são preponderantemente quantitativas, e não qualitativas (SUCHMAN; MERTZ, 2010, p. 555-579).

A versão da base de dados utilizada nesta pesquisa está em formato MySQL e contém informações até abril de 2016, incluindo dados sobre processos autuados, nomes das partes e registros de andamentos. Também fazem parte da base metadados sobre os processos, como o assunto jurídico, o órgão judicial de origem e o estado de procedência. Os andamentos abrangem informações sobre datas e resultados de decisões tomadas durante os processos, datas de distribuição dos processos, datas de conclusão ao relator do processo, trânsito em julgado e similares.

\section{Resultados}

Entre as ações que mais cresceram no Supremo na última década estão as de direito do consumidor (FALCÃO et al., 2014, p. 16). A Oi é a primeira das 20 empresas privadas com mais ações desse tipo tramitando no Tribunal. Essas empresas são todas reguladas por agências e/ou são concessionárias.

\footnotetext{
4 Há várias décadas os pesquisadores já haviam identificado os ganhos do uso da informática na pesquisa sobre comportamento judicial. Ver, por exemplo, Schubert (1968, p. 60): "The computer is a useful instrument in research in behavioral jurisprudence because (1) it facilitates inquiry by reducing time costs, thus freeing the investigator for routine operations [...] (2) it makes feasible many types of inquiry that could not have been undertaken heretofore [...] and (3) it provides, increasingly, better data (in the sense of empirical observations that have been transformed by the researcher into quantified units suitable for measurement manipulations) by making feasible a greatly expanded repertoire of alternative modes of analysis."
} 
Tabela 1 - Principais autores de processos no STF em demandas consumeristas

\begin{tabular}{|c|c|}
\hline Empresa & Total de processos \\
\hline $\mathrm{OI}$ & 6271 \\
\hline Banco Santander Brasil S/A & 3136 \\
\hline Banco do Brasil S/A & 2983 \\
\hline Bradesco & 1733 \\
\hline Vivo S/A & 1367 \\
\hline Unimed & 354 \\
\hline Rio Grande Energia S/A & 343 \\
\hline Banco ABN Amro Real S/A & 320 \\
\hline BV Financeira S/A - Crédito, Financiamento e Investimento & 300 \\
\hline Companhia de Eletricidade do Estado da Bahia (Coelba) & 272 \\
\hline HSBC Bank Brasil S/A - Banco Múltiplo & 252 \\
\hline Itaú Unibanco S/A & 232 \\
\hline Aymoré Crédito, Financiamento E Investimento S/A & 225 \\
\hline Banco Panamericano SA & 221 \\
\hline Banco BMG S/A & 216 \\
\hline Caixa Econômica Federal (CEF) & 201 \\
\hline Centro Trasmontano de São Paulo & 185 \\
\hline Golden Cross Assistência Internacional de Saúde Ltda & 179 \\
\hline Elektro Eletricidade e Serviços S/A & 168 \\
\hline Banco Cruzeiro do Sul S/A & 158 \\
\hline
\end{tabular}

Fonte: os autores.

Segundo dados do projeto Supremo em Números, da FGV Direito Rio, entre janeiro de 2011 e março de 2016, a Oi teve uma média de mais de três novos processos por dia no Supremo. Foram exatamente 6.271 casos. Esse fluxo de litigância de uma só empresa no principal tribunal do País é provavelmente inédito em termos globais. Mais de três processos por dia. Digno do Guinness World Book of Records. Inédito, inclusive, em termos dos Estados Unidos, de onde vêm as inspirações da modelagem de regulação.

A taxa de sucesso dos recursos apresentados no Supremo no mesmo período é de no máximo 3,04\%. Isso entre os recursos extraordinários, agravos em recurso extraordinário e agravos de instrumento. Ou seja, para cada 100 processos julgados, menos de quatro têm resultado positivo. Pelo menos 96 foram aparentemente judicialmente inúteis. 


\section{Taxa de Sucesso em \% em Recursos no STF (2011-2016)}

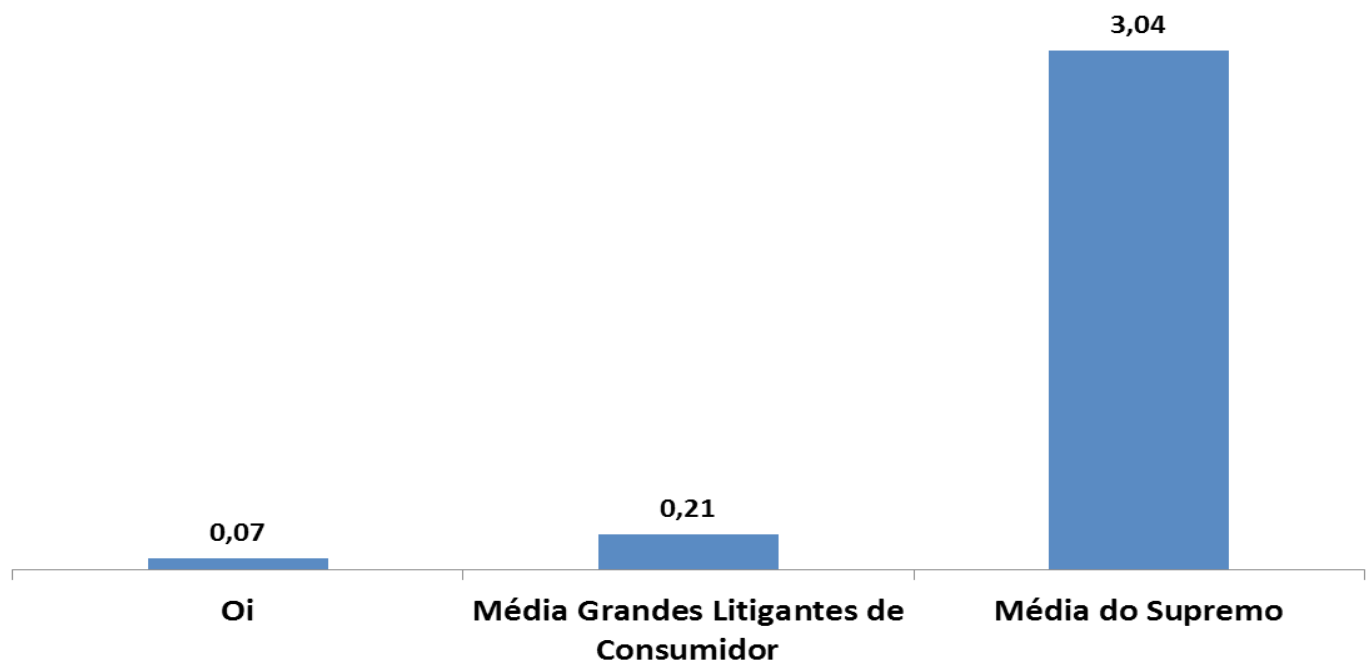

Fonte: os autores.

$\mathrm{Na}$ área do direito do consumidor, a taxa de sucesso é pior. Apenas 0,21\%, ou menos, dos recursos contra consumidores têm sucesso. O que significa que a imensa maioria dos recursos contra decisões favoráveis ao consumidor é aparentemente inútil.

A taxa de sucesso da Oi é, no entanto, ainda menor. A empresa tem sucesso em, no máximo, 0,07\% dos recursos. Ou seja, das mais de 10 mil decisões proferidas nos mais de seis mil casos na Corte, não mais do que sete foram favoráveis à Oi.

O Gráfico 2 revela parcialmente a natureza desses processos.

Gráfico 2 - Temas dos Recursos da Oi no STF (2011-2016)

Temas dos Recursos da Oi no STF (2011-2016)

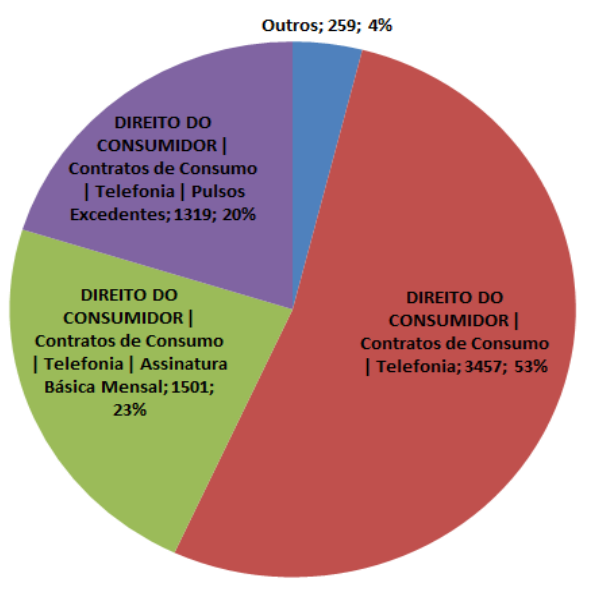

Fonte: os autores. 
O Tribunal de origem dessas ações está apresentado no Gráfico 3. Pela estrutura ideal do Poder Judiciário, elas deveriam ter início e fim nos juizados especiais.

Gráfico 3 - Origem dos Processos da Oi no STF (2011-2016)

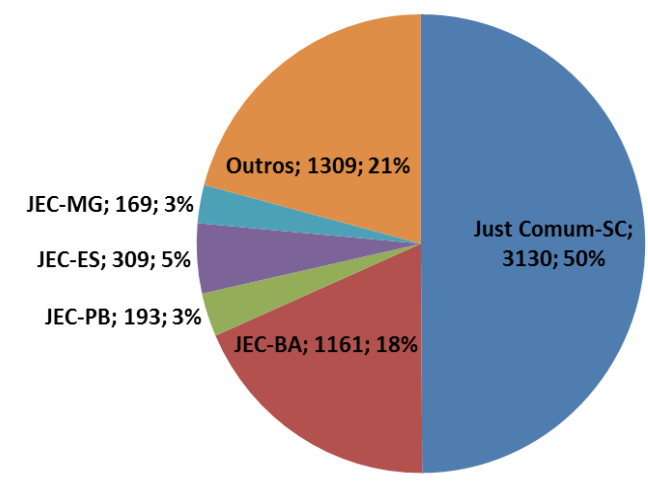

Fonte: os autores.

Duas conclusões preliminares podem ser retiradas desse diagnóstico.

Primeiro, a Oi não entende o Judiciário como risco. Inexiste incerteza diante do Supremo. Existe certeza. A Oi sabe de antemão que vai perder. Se ainda assim tenta número recorde de recursos é porque não se preocupa em perder. Perder, isto é, adiar o reconhecimento e o ressarcimento do direito lesado do consumidor, compensa. Segundo, diante do número de recursos perdidos e do primeiro lugar da $\mathrm{O}$, não estamos diante de conflitos individualizados entre a Oi e um ou outro usuário de telefonia. Estamos diante de uma amostragem de uma política empresarial de judicialização de suas obrigações constitucionais não cumpridas.

Trata-se de exemplo da judicialização da ineficiência empresarial.

Essa política, aparentemente legal, no fundo constitui abuso do direito de recorrer, estabelecido pelo artigo $5^{\circ}, \mathrm{LV}^{5}$ da Constituição Federal. É verdadeiro bullying, assédio processual.

Sua rationale se fundamenta em simples cálculos de custo e benefício, tanto financeiro quanto estratégico. $O$ cálculo financeiro é obvio e intuitivo. O custo judicial (all included, isto é, os custos internos e externos à empresa) é menor do que os custos de investimento e custeio para a empresa eliminar a ineficiência de seus serviços e atender seus consumidores.

Essa política de judicialização da ineficiência não é novidade no caso da Oi. A Empresa decorre originariamente da Telemar, que em 1998 ganhou o lote das teles do Rio de Janeiro e de outros 15 estados durante a privatização dos serviços de telefonia no Brasil. Foi privatização temerária.

\footnotetext{
$\overline{5}$ Art. $5^{\circ}$ Todos são iguais perante a lei, sem distinção de qualquer natureza, garantindo-se aos brasileiros e aos estrangeiros residentes no País a inviolabilidade do direito à vida, à liberdade, à igualdade, à segurança e à propriedade, nos termos seguintes: [...] LV - aos litigantes, em processo judicial ou administrativo, e aos acusados em geral são assegurados o contraditório e ampla defesa, com os meios e recursos a ela inerentes; [...]
} 
O grupo econômico vencedor não dispunha de recursos financeiros para realizar os investimentos necessários para assegurar a qualidade dos serviços ao consumidor a que se obrigara.

A judicialização em massa no Tribunal de Justiça do Rio de Janeiro, como indicador da insatisfação dos consumidores, começa já nos anos 1990. A Telemar aceita essa judicialização para adiar suas obrigações. Os juros de empréstimos de mercado eram maiores do que os custos judiciais. ${ }^{6}$

Essa judicialização da ineficiência empresarial foi pioneira no Brasil. Exemplar. Abriu caminho para outras empresas reguladas e concessionárias de serviços públicos. Quanto maior o prazo da judicialização, mais reduzidos os custos financeiros das empresas. A partir daí os advogados fizeram o resto. Recursos atrás de recursos, com auxílio da doutrina processual adotada pelos próprios tribunais. Desconfiguraram, em parte, os juizados especiais e abriram vias inéditas de ascensão ao Supremo.

A Tabela 2, de pesquisa do CNJ que identificou os 100 maiores litigantes do Brasil (CONSELHO NACIONAL DE JUSTIÇA, 2012), confirma o quadro inicial e mostra os maiores litigantes do Brasil. Além do governo, todas as empresas privadas ou são reguladas ou são concessionárias.

Tabela 2 - Listagem dos 100 maiores litigantes contendo o percentual de processos em relação aos 100 maiores litigantes da Justiça

\begin{tabular}{|c|c|c|c|c|c|c|c|c|}
\hline \multirow{2}{*}{ Rank } & \multicolumn{8}{|c|}{ Cem maiores Litigantes } \\
\hline & \multicolumn{2}{|l|}{ Nacional (\%) } & \multicolumn{2}{|l|}{ Justiça Federal (\%) } & \multicolumn{2}{|c|}{ Justiça do Trabalho (\%) } & \multicolumn{2}{|c|}{ Justiça Estadual (\%) } \\
\hline 1 & $\begin{array}{l}\text { INSS - Instituto } \\
\text { Nacional do Se- } \\
\text { guro Social }\end{array}$ & 22,33 & $\begin{array}{l}\text { INSS - Instituto Nacio- } \\
\text { nal do Seguro Social }\end{array}$ & 43,12 & União & 16,73 & $\begin{array}{l}\text { Estado do Rio } \\
\text { Grande do Sul }\end{array}$ & 7,73 \\
\hline 2 & $\begin{array}{l}\text { CEF - Caixa } \\
\text { Econômica Fe- } \\
\text { deral }\end{array}$ & 8,50 & $\begin{array}{l}\text { CEF - Caixa Econômica } \\
\text { Federal }\end{array}$ & 18,24 & $\begin{array}{l}\text { INSS - Instituto } \\
\text { Nacional do Segu- } \\
\text { ro Social }\end{array}$ & 6,41 & $\begin{array}{l}\text { Banco do Brasil } \\
\text { S/A }\end{array}$ & 7,12 \\
\hline 3 & $\begin{array}{l}\text { Fazenda Nacio- } \\
\text { nal }\end{array}$ & 7,45 & Fazenda Nacional & 15,65 & $\begin{array}{l}\text { CEF - Caixa Eco- } \\
\text { nômica Federal }\end{array}$ & 5,29 & $\begin{array}{l}\text { Banco Bradesco } \\
\text { S/A }\end{array}$ & 6,70 \\
\hline 4 & União & 6,97 & União & 12,77 & $\begin{array}{l}\text { Grupo CEEE - } \\
\text { Companhia Es- } \\
\text { tadual de Energia } \\
\text { Elétrica }\end{array}$ & 5,22 & $\begin{array}{l}\text { INSS - Institu- } \\
\text { to Nacional do } \\
\text { Seguro Social }\end{array}$ & 5,95 \\
\hline 5 & $\begin{array}{l}\text { Banco do Brasil } \\
\text { S/A }\end{array}$ & 4,24 & $\begin{array}{l}\text { Advocacia Geral da } \\
\text { União }\end{array}$ & 1,75 & $\begin{array}{l}\text { Banco do Brasil } \\
\text { S/A }\end{array}$ & 4,82 & Banco Itaú S/A & 5,92 \\
\hline 6 & $\begin{array}{l}\text { Estado do Rio } \\
\text { Grande do Sul }\end{array}$ & 4,24 & $\begin{array}{l}\text { FUNASA - Fundação } \\
\text { Nacional de Saúde }\end{array}$ & 0,79 & Telemar S/A & 4,31 & $\begin{array}{l}\text { Brasil Telecom } \\
\text { Celular S/A }\end{array}$ & 5,77 \\
\hline 7 & $\begin{array}{l}\text { Banco Bradesco } \\
\text { S/A }\end{array}$ & 3,84 & $\begin{array}{l}\text { INCRA - Instituto Na- } \\
\text { cional de Colonização e } \\
\text { Reforma Agrária }\end{array}$ & 0,48 & $\begin{array}{l}\text { Petrobras - Petró- } \\
\text { leo Brasileiro S/A }\end{array}$ & 3,80 & $\begin{array}{l}\text { Banco Finasa } \\
\text { A/A }\end{array}$ & 4,08 \\
\hline 8 & Banco Itaú S/A & 3,43 & $\begin{array}{l}\text { EMGEA - Empresa Ges- } \\
\text { tora de Ativos }\end{array}$ & 0,47 & Fazenda Nacional & 3,29 & $\begin{array}{l}\text { Município de } \\
\text { Manaus }\end{array}$ & 3,81 \\
\hline 9 & $\begin{array}{l}\text { Brasil Telecom } \\
\text { Celular S/A }\end{array}$ & 3,28 & $\begin{array}{l}\text { IBAMA - Instituto Bra- } \\
\text { sileiro do Meio Ambien- } \\
\text { te dos Recursos Natu- } \\
\text { rais Renováveis }\end{array}$ & 0,47 & Banco Itaú S/A & 2,89 & $\begin{array}{l}\text { Município de } \\
\text { Goiânia }\end{array}$ & 3,76 \\
\hline 10 & $\begin{array}{l}\text { Banco Finasa } \\
\mathrm{A} / \mathrm{A}\end{array}$ & 2,19 & $\begin{array}{l}\text { BACEN - Banco Central } \\
\text { do Brasil }\end{array}$ & 0,39 & $\begin{array}{l}\text { Banco } \\
\text { S/A }\end{array}$ & 2,81 & $\begin{array}{l}\text { Banco Santan- } \\
\text { der Brasil S/A }\end{array}$ & 3,14 \\
\hline
\end{tabular}

$\overline{6}$ Sobre o tema, ver Falcão (2012). 


\section{Discussão dos resultados}

Poderíamos dizer que este é o resultado líquido, no âmbito judicial, do atual modelo de regulação das agências e do atual modelo de privatização de serviços públicos.

Não são poucos os economistas que desenham esses números, considerando-os, ao contrário, indicadores do sucesso das atuais políticas. Mas o mero cálculo de custos e benefícios da judicialização não é suficiente para explicar essa política. Afinal, cerca de seis mil casos no Supremo para uma empresa que tem 70 milhões de usuários em 25 estados pouco significa em ganhos financeiros.

Para se ter uma ideia completa dos benefícios da judicialização da ineficiência empresarial, necessitaríamos de dois outros dados.

Primeiro, o número de ações que entraram na primeira instância e foram decididas até chegarem ao Supremo, no caso da Oi, nos Estados de Santa Catarina e Bahia, o que, nesse momento, é impossível dada a ausência de estatísticas judiciais transparentes e comparáveis.

Estamos diante, por um lado, de uma política de judicialização de empresas de âmbito nacional ou transestaduais e, de outro, de um Poder Judiciário fragmentado em suas próprias informações. Essa fragmentação estatística impede o Judiciário de se autodefender.

Como em toda guerra, um dos elementos mais eficientes são as técnicas e estratégias dissuasórias do adversário. Eis aqui o segundo ponto crucial do assédio processual. Os mais de seis mil casos são uma mensagem clara ao consumidor: a Oi se dispõe a uma política de judicialização de sua ineficiência ad extremis.

Aquele que pretenda reclamar no Judiciário terá que arcar com os custos do litígio. Terá que estar preparado para pagar o custo de litigar na primeira, na segunda (tribunal estadual), na terceira (Superior Tribunal de Justiça) e na quarta instâncias (Supremo). Ora, são poucos, muito poucos, os usuários que a tanto se dispõem ou têm recursos para tal, e cujas indenizações buscadas sejam compensatórias. Aliás, os litigantes na área de consumo são primordialmente as mulheres, conforme pesquisa de Pinheiro e Barbosa Filho (2014) que buscaram entender as características socioeconômicas, demográficas e geográficas as quais resultam na busca pelos serviços da justiça. ${ }^{7}$ Os pesquisadores identificaram que a Justiça Comum foi a instituição com menor proporção de conflitos resolvidos, ficando atrás dos juizados, dos Procons, dos amigos e parentes. E mais. A proporção de conflitos efetivamente resolvidos pela justiça caiu significativamente entre 1988 e 2009, de 57,6\% para 45,6\%, em todas as regiões do País. ${ }^{8}$

\footnotetext{
"Os resultados mostram que as mulheres buscam mais a justiça do que os homens para a resolução de seus conflitos de consumo, enquanto ocorre o contrário no que se refere às questões trabalhistas." PINHEIRO; BARBOSA FILHO (2014).

8 "Os Procons e amigos e parentes foram as instituições mais eficazes em produzir soluções. Os juizados especiais, por sua vez, também mostraram uma taxa de sucesso maior que a média, enquanto a justiça comum foi a instituição com menor proporção de conflitos resolvidos. Isso atesta a importância de se contar com essas outras instituições de solução de conflitos. Um resultado preocupante, porém, é que a proporção de conflitos resolvidos pela justiça caiu significativamente entre 1988 e 2009: de 57,6\% para 45,6\% (incluindo os juizados especiais). Essa queda ocorreu em todas as regiões do país." (PINHEIRO,; BARBOSA FILHO (2014).
} 
Não existe ação judicial grátis. Os custos não são somente os das partes litigantes. Incluem custos públicos do Poder Judiciário, Ministério Público, Defensoria e tanto mais. Custos de remuneração de juízes, de serventuários, de uso de imóveis, de custeio, de tecnologias, de aposentadorias e por aí vamos.

Ao usar o direito de recorrer para adiar a perda, a Oi unilateralmente impõe esses custos ao Judiciário. O Judiciário os transfere para o Orçamento Público. O Orçamento público os transfere para quem paga imposto: o contribuinte, o consumidor. O eleitor, inclusive. Hoje, os mesmos.

Em resumo. A ineficiência da Oi é subsidiada e alimentada pelo Estado. E contribui para a ineficiência do próprio Judiciário. Como evitar esse bullying, assédio processual?

Primeiro de tudo é preciso reconceituar o que seja conflito de consumo e essa decorrente política. A contrário do que se imagina, esta política não é contra o consumidor. É contra o orçamento público, ou seja, em nosso caso, alimentadora do déficit público, via despesas do Poder Judiciário. Mas, sobretudo, é contra a concorrência entre empresas em que o indicador é a eficiência. No fundo, assim como na Lava Jato, o mesmo ocorre com essa política de judicialização. Na Lava Jato evidenciou-se que era uma competição não centrada na eficiência empresarial, mas na capacidade de corromper mais. A política da judicialização da ineficiência não é centrada na eficiência da prestação de serviços, mas em boa parte na neutralização judicial da insatisfação do consumidor.

Essa neutralização aponta diretamente para a importação seletiva por políticos e economistas do modelo de regulação e privatização de serviços públicos. Esses modelos são possíveis apenas se ao mesmo tempo os consumidores tiverem poder de voz, de ação e, sobretudo, de judicializar sua insatisfação.

Nos Estados Unidos isso tem sido viabilizado somente porque existem as Class Actions (ações coletivas), que transformam os consumidores e os advogados em parceiros da eficiência regulatória e fiscal da qualidade dos serviços das concessionárias.

\section{Conclusão}

A janela de oportunidades para novas privatizações, como agora se diz, deveria ser também uma janela de oportunidades, não para reformar o Poder Judiciário, por inteiro. Esqueçam. Esta é estratégia para a não reforma. Mas um novo modelo de privatização e de regulação exigiria a adoção de mecanismos processuais, como as Class Actions, por exemplo, que tanto temem as empresas reguladas e concessionárias. E com razão. Consistiria em uma contribuição decisiva para implantar a fair competition no Brasil.

Na verdade, é crescente a necessidade de análises macroeconômicas se aliarem a análises macrojudiciais. Hoje, a análise macroeconômica se alia à microjudicialização, aquela que percebe litígios como iniciativas individuais, seja de empresas, seja de indivíduos. E a análise macrojudicial inexiste.

Não espanta o melancólico fim. 
O Supremo mostra-se inerte diante do abuso. É como se pudesse tudo, poder maior, mas é incapaz de evitar o assédio processual promovido pela Oi nos últimos cinco anos. Se não fosse a Oi a primeira colocada, seria outra telefônica ou banco.

Os modelos econômicos de privatização não protegem suficientemente os consumidores dos conflitos que as próprias agências, com suas normas e falta de fiscalização, e as concessionárias, com suas práticas, geram. Omitem-se. Mesmo quando multam, não cobram. ${ }^{9}$

Conflitos com o consumidor não são com eles. Deixam tudo para o Judiciário resolver. Depois se queixam da interferência dos juízes. Novos modelos de privatizações são necessários para abrir o futuro que ainda nos está fechado pela falta de análise objetiva do passado.

\section{Referências}

BORBA, Julia. Anatel aplica R \$ 1,9 bilhão em multas, mas só arrecada R \$ 90 milhões. Folha de São Paulo, 06 jun. 2014. Disponível em: <http://www1.folha.uol.com.br/mercado/2014/06/1466466-anatel-aplica-r-19-bilhao-em-multas-mas-so-arrecada-r-90-milhoes.shtml>. Acesso em: 22 jul. 2016.

CONSELHO NACIONAL DE JUSTIÇA. 100 maiores litigantes. Departamento de Pesquisas Judiciárias, 2012. Disponível em: <http://www.cnj.jus.br/images/pesquisas-judiciarias/Publicacoes/100_ maiores_litigantes.pdf>. Acesso em: 20 jul. 2016.

DIAMOND, Shari Seidman; MUELLER, Pam. Empirical legal scholarship in law reviews. Annual Review of Law and Social Science, v. 6, p. 581-599, 2010.

EPSTEIN, Lee; KING, Gary. Building an infrastructure for empirical research in the law. Journal of Legal Education, v. 53, i. 3, 2003.

FALCÃO, Joaquim; CERDEIRA, Pablo; ARGUELHES, Diego Werneck. I Relatório Supremo em Números. O Múltiplo Supremo. Rio de Janeiro: FGV Direito Rio, 2011.

FALCÃO, Joaquim. Diante do consumidor, Anatel é mais 'ausente'. Folha de São Paulo, 29 jul. 2012.

FALCÃO, Joaquim et al. II Relatório Supremo em Números. O Supremo e a Federação entre 2010 e 2012. Rio de Janeiro: FGV Direito Rio, 2014.

HARTMANN, Ivar A.; FERREIRA, Lívia da Silva; REGO, Bianca Dutra da Silva. Deferência ao fiscal da lei? A probabilidade de sucesso do PGR nas ações diretas de inconstitucionalidade. Revista de Estudos Empíricos em Direito, v. 3, n. 1, 2016.

HUDSON, Alexander; HARTMANN, Ivar Alberto. Can you bury ideology? An empirical analysis of the ideal points of the Ministers of Brazil's Supremo Tribunal Federal. Revista de Direito Administrativo e Constitucional, v. 17, i. 68, 2017.

9 Em 2013 a Anatel aplicou R \$ 1,9 bilhões em multas, mas arrecadou efetivamente apenas R \$ 90 milhões - menos de 5\% (BORBA, 2014). 
PINHEIRO, Armando Castela; BARBOSA FILHO, Fernando de Holanda. Os determinantes da Demanda pelo judiciário. Instituto Brasileiro de Economia, jul. 2014. Disponível em: <http://portalibre.fgv.br/main.jsp?lumPageId=402880811D8E34B9011D9CCBFDD1784C\&contentId=8A7C82C546FCECF5014716CEDB233DBD>. Acesso em: 19 jun. 2016.

SCHUBERT, Glendon. The Importance of Computer Technology to Political Science Research in Judicial Behavior. Jurimetrics Journal, v. 8, 1968.

SUCHMAN, Mark C.; MERTZ, Elizabeth. Toward a new legal empiricism: empirical legal studies and new legal realism. Annual Review of Law and Social Science, v. 6, p. 555-579, 2010.

VERONESE, Alexandre. O problema da pesquisa empírica e sua baixa integração na área de Direito: uma perspectiva brasileira da avaliação dos cursos de pós-graduação do Rio De Janeiro. Congresso Nacional do CONPEDI, 16., 2007, Belo Horizonte. Anais... Belo Horizonte, 2007. Disponível em: <http://www.conpedi.org.br/manaus/arquivos/anais/bh/alexandre_veronese2.pdf>. Acesso em: 11 nov. 2012.

WIZIACK, Julio et al. Oi pede recuperação judicial de R \$ 65 bilhões, a maior da história do Brasil. Folha de São Paulo, 20 jun. 2016. Disponível em <http://www1.folha.uol.com.br/mercado/2016/06/1783621-oi-pede-recuperacao-judicial-de-r-53-bilhoes.shtml>. Acesso em: 09 ago. 2017.

YANOW, Dvora; SCHWARTZ-SHEA, Peregrine (Ed.). Interpretation and method: empirical research. Methods and the interpretive turn. M. E. Sharpe, 2006.

Data da submissão: 29 de setembro de 2016 Avaliado em: 29 de novembro de 2016 (AVALIADOR A) Avaliado em: 08 de dezembro de 2016 (AVALIADOR B) Avaliado em: 27 de março de 2017 (AVALIADOR C) Aceito em: 10 de maio de 2017 
